\title{
Research on the Reform Path of University Library's Supply Side in the Context of New Era
}

\author{
Yuan $\mathrm{GaO}^{1, *}$ \\ ${ }^{1}$ Zhuhai College of Science and Technology, Zhuhai, Guangdong 519041, China \\ *Corresponding author. Email: 173403910@qq.com
}

\begin{abstract}
As an important part of the school, the university library is an academic institution that serves teaching and scientific research with main service objects of teachers and students. After clarifying the reading connotation of university library readers against the background of the new era, through the analysis of the current situation and existing problems of the supply side of university libraries, it is found that insufficient effective communication, relatively single reading carrier, insufficient interactivity of reader activity, and monotonous reading space and environment restrict the development of university libraries. In the context of the new era, university libraries should start from themselves, keep up with the pace of the times, focus on readers to reform from the supply side, establish effective communication by setting up full-time departments, multifariously enrich library resources with pertinence, realize the diversification of resource carriers and independent diversification of channels, carry out interactive brand activities while enhancing interactivity and understanding the needs of readers, improve the quality and efficiency of library services, and let the resources and services of libraries adapt to the diverse needs of users, so as to promote the sustainable and healthy development of libraries and contribute to the development of universities and society.
\end{abstract}

Keywords: New era, University library, Supply side.

\section{INTRODUCTION}

In the context of the new era, with the development of information and the advancement of technology, the reading habits of teachers and students are also changing. If the traditional library model is still used to provide reader services for teachers and students, it will not help cultivate students to develop good reading habits and will not be able to provide teachers and researchers with more effective reference and consulting services, not to mention "meeting the growing spiritual and cultural needs of readers". University libraries should start from themselves, keep up with the pace of the times, carry out reforms from the supply side, improve service quality, and meet the needs of readers.

\section{CLARIFYING THE READING CONNOTATION OF UNIVERSITY LIBRARY READERS AGAINST THE BACKGROUND OF THE NEW ERA}

In recent years, nationwide reading has triggered an upsurge in society, and all parts of the country have worked hard to build a scholarly society. Beginning in 2015, the "National Reading Month" activities carried out across the country have been splendid: activities such as "Everyone Reads a Good Book, Jointly Building the Chinese Dream", "Internet + Reading", and "Let the Fragrance of Books Permeate Jilin Province" with different themes and forms lead the life style of nationwide reading in various cities. However, according to the data of the 14th National Reading Survey released by the Chinese Academy of Press and Publication, on the one hand, nearly $70 \%$ of the people looked forward to holding reading activities; on the other hand, more than $60 \%$ of the people 
expressed average or dissatisfaction with their overall reading situation. The library is an important place for the storage and custody of human knowledge. When the new fashion of nationwide reading is permeating the society, the colleges and universities in the ivory tower are the main force of its high end. University libraries are facing unprecedented new opportunities and challenges. Providing readers with more highquality and efficient services has become a top priority, and reforms on the supply side are imperative.

The connotation of "reading" is not the basic element of reform, but clarifying the connotation of "reading" is the primary condition for deeply understanding the needs of readers and effectively carrying out the reform of the library's supply side. Only on the basis of clarifying the connotation of reading, can libraries carry out targeted services according to different needs. Broadly speaking, all learning behaviors can be called reading. Learning behavior includes two aspects. The first is practical learning, that is, professional learning or database use with the main purpose of scientific research, studies, and examinations; the second is the study to improve self-cultivation and humanistic temperament, including but not limited to the reading of philosophy, culture, art, history, novel, and life book.

For readers of the first aspect of learning behavior, their main needs are diversified and comprehensive literature resources and a comfortable reading environment that meets individual reading habits. Readers will read and learn on their own according to external pressure or actual needs. The second aspect of reading behavior requires university libraries to conduct guiding and colorful reading promotion activities while providing diversified resources and a comfortable reading environment, so as to improve the quality of reader services and create a good reading atmosphere for readers and strengthen reading guidance at the same time, so that reading becomes a conscious activity of readers.

\section{CURRENT SITUATION AND PROBLEMS OF THE SUPPLY SIDE OF UNIVERSITY LIBRARIES}

As the storage center of human knowledge, the library has the functions of collecting, sorting and collecting books and reference materials for people to read, refer to, preserve human cultural heritage, develop information resources, and participate in social education. With the rapid development of information technology and national economy, libraries are no longer restricted by time and space, and library user groups are developing in a diversified and dynamic direction. The library faces a series of problems. The relatively lagging service model and the inability of the types and quality of information resource supply to meet the all-round needs of readers will become obstacles to the sustainable development of the library.

\subsection{The Effective Communication Between the Library and Readers Is Not Sufficient, and the Needs of Readers Cannot Be Timely Understood}

Effective communication between the library and readers is an important part of library public relations. Communication with readers is one of the most basic ways in which libraries provide services on a daily basis and is an important part of carrying out reader services. Whether librarians and readers can communicate effectively directly affects the efficiency and quality of reader services and the image of librarians in the eyes of readers. Librarians' weak service awareness and lack of communication skills, and readers' ideological and moral qualities and language barriers are all important factors that affect communication.

\subsection{The Provision of Reading Carriers Is Relatively Single and Cannot Adapt to the Changes in Readers' Reading Habits}

With the popularity of the Internet and the advent of the era of big data, readers' information needs have become more comprehensive and integrated, and readers' reading habits have also changed. In addition to the rapid growth in demand for digital resources, readers are no longer satisfied with several relatively traditional reading carriers. If the library fails to adapt to this change and cannot respond positively in a timely manner, it will not be able to meet the diverse and diversified reading needs of various types of users.

With the development of education and scientific research, the needs of university library readers follow the latest development direction and trends in this field to carry out corresponding research, and the information needs are becoming more professional, in-depth and special. The traditional service form has been apparently single. Readers need a series of high-level information 
services such as deeper discipline services, decision-making consulting services, comparative analysis of scientific research competitiveness, discipline competitiveness analysis, and academic frontier development analysis and so on. However, limited by the talents' majors and capabilities of the library, it is difficult to meet the discipline development needs of scientific research users who need more professional, targeted and personalized services.

\subsection{The Interactivity of Reader Activities Needs to Be Further Improved}

Many university libraries are working hard on reading promotion, and various explorations are at the forefront of their peers. But in general, the links and forms of reader participation are relatively simple, fragmented, and without strict regulations, which are temporary and accidental. As the main force in the construction of campus culture, libraries must continuously innovate the main body and form of reading promotion activities. Highly interactive reader activities are more likely to attract more teachers and students to participate. The more disciplines of reading promotion activities, the more diversified the sources, the more conducive it is to the diversification of the forms of reading promotion activities, and the more favorable it is to attract more teachers and students to borrow and study in the library.

\subsection{The Reading Space Environment Is Monotonous, Failing to Meet the Individual Needs of Readers}

Whether it is a public library or a university library, both provide a comfortable and quiet learning space for readers. In recent years, with the advancement of science and technology, China's economy has developed rapidly, and the building structure of the library has become more and more multifunctional and intelligentized, and the setting of reading spaces has become more and more diversified. Compared with social public libraries, the space setting of university libraries is relatively monotonous, and many university libraries cannot meet the research and communication needs of teachers and the reading needs of students.

\section{THE REFORM PATH OF THE SUPPLY SIDE OF UNIVERSITY LIBRARIES}

\subsection{Establishing a Full-time Department for External Communication and Cooperation}

As an important part of the school, university libraries are academic institutions that serve teaching and scientific research, and their service objects are mainly teachers and students. It goes without saying that the library is the main body of reading promotion. In order to allow university libraries and readers to communicate better and promote the establishment of a harmonious relationship between the two, not only the library leaders need to pay attention to it, but also a fulltime department is needed to be responsible for the organization and management of reading promotion and the planning and execution of promotion activities. The full-time department must coordinate with the specific needs of the library to manage student volunteers, book clubs and other related student associations, and the full-time department need to communicate and cooperate with relevant functional departments inside and outside the school.

\subsection{Multifariously Enriching Library Resources with Pertinence}

In today's "Internet +" era, it is necessary to pay attention not only to the supplement of traditional paper library collection, but also to the construction of electronic mobile carrier resources that meet the needs of modern reading. The library's book procurement work should solicit readers' opinions extensively, provide multiple channels for readers to construct purchases, analyze borrowing data based on readers' feedback, and replenish collections in a timely manner. It is needed to compress the acquisition and editing process of books on Amazon and Dangdang bestseller lists and put them on the shelves for borrowing in the special borrowing area of each branch library as soon as possible. At the same time, relevant bibliographic information should be released in time, and the volume of copies of classic books and best-selling books should be appropriately increased based on real-time borrowing data to ensure that readers' borrowing needs are met. Efforts should be made to make full use of the information display equipment and the library 
management system for electronic data interchange and display readers' book reviews, popular books and other information in an all-round way; it is also needed to promote reading bookshelf terminals and increase the collection of EPUB e-books in mobile libraries to meet modern reading needs such as ubiquitous reading and fragmented reading.

\subsection{Realizing the Diversification of Reading Carriers}

Only by realizing the diversification of reading carriers can the promotion of reading keep up with the times. Due to the development of information technology network, the carrier of reading has undergone earth-shaking changes. Therefore, reading promotion should not only pay attention to traditional paper reading, but also use modern technology to meet the needs of modern reading. It is also necessary to vigorously promote screen reading, and allow reading to enter readers' lives in an all-round way through paper reading, computer reading, mobile phone reading, and video reading. At present, mobile reading and traditional paper book reading are basically separated. Therefore, attention should be paid to the promotion of $\mathrm{e}$ books and reading data statistics and targeted digital processing should be carried out to enrich the carrier of reading.

\subsection{Expanding Reading Promotion Channels and Carrying out Interactive Reader Activities}

The diversification and novelty properties of reading promotion channels stimulate readers' interest, thereby reducing the resistance to reading promotion. The promotion work of colleges and universities is concentrated on campus, and they generally have channels for communicating and promoting with readers. However, traditional publicity and promotion channels are well used, and the application and interactivity of new media are poor. Therefore, it is necessary to actively construct publicity channels with its own characteristics and use third-party media to expand promotion channels.

It is needed to form a properly configured reading promotion team, fully mobilize the subjective initiative of the reader group in activities, let readers participate in the planning, organization, implementation and evaluation of reading promotion activities, and constantly innovate methods to fully mobilize the enthusiasm of various reader groups to participate in reading promotion activities. Efforts should be made to let readers participate in every link of reading promotion activities.

\subsection{Integrating Space Resources to Provide a Multifunctional Reading and Communication Platform}

As the hall of knowledge learning, the library should not only be a single "database" or "study room" providing documentary resources and reading environment, but also a stage and a hall for readers to exchange knowledge with each other. According to the characteristics of the discipline construction of the college, the library of Zhuhai College of Science and Technology fully investigates the needs of teachers and students and has set up "Shared Space", "English Corner", "Seminar Room" and other functional rooms in the library to provide readers with a variety of learning and communication spaces, so that readers can not only experience the fun of reading in university libraries, but also communicate and interact.

\subsection{Making Full Use of the Volunteer Advantages of Colleges and Universities}

University libraries have a natural advantage in attracting reader volunteers. Therefore, adopting the "librarian team + student volunteer organization" model to carry out reading promotion work not only saves the manpower cost of the library, but also fully mobilizes the enthusiasm of readers for participation, fundamentally changing the current situation of the lack of persistence and effectiveness of reading promotion due to a series of temporary activities carried out by university libraries.

\section{CONCLUSION}

The reform of the supply side of university libraries can not only improve the quality and efficiency of the service supply side of the library and adapt the resources and services of the library to the diverse needs of users, but also promote the sustainable and healthy development of the library in the future. Only by expanding its service content, innovating its service model, and promoting the obvious improvement of its service supply quality, can university libraries be favored by more readers, give full play to their value and role, and contribute to the development of universities and society. 


\section{AUTHORS' CONTRIBUTIONS}

Gao.

This paper is independently completed by Yuan

\section{REFERENCES}

[1] Zhang Jie, Zhang Qingli. Making Nationwide Reading a Life Style, Social Sciences in China, December 2015. (in Chinese)

[2] Wang Shu, Wei Qunyi, Huang Juan. Theoretical Framework and Practice of Reading Promotion in University Libraries: Taking Chongqing University Library as an Example, Library and Information Service, June 2014. (in Chinese)

[3] Long Qi. Research on the Strategy of Service Transformation and Upgrade of University Library Against the Background of Supplyside Reform, Western China Quality Education, July 2017. (in Chinese)

[4] Lu Renyan, Li Ming, Liu Jingjing. Research on the Library Service Innovation Under the Guidance of Supply-side Reforms, Journal of Library and Information Sciences in Agriculture, December 2016. (in Chinese)

[5] Wu Ruizhen. Research on the Effectiveness of Communication Between Library and Readers, Journal of Chifeng University (Natural Science Edition), March 2012. (in Chinese)

[6] Dai Yan. Research on the Reader Participation Path of Reading Promotion Activities in University Libraries, Modern Society, Issue 16, 2019. (in Chinese) 